\title{
Comparable results between crosslinked polyethylene and conventional ultra-high molecular weight polyethylene implanted in total knee arthroplasty: systematic review and meta-analysis of randomised clinical trials
}

\author{
Alessandro Bistolfi ${ }^{1}\left[\right.$ - Fortunato Giustra ${ }^{2} \cdot$ Francesco Bosco $^{2}$. Carlotta Faccenda ${ }^{2} \cdot$ Marianna Viotto $^{2}$. \\ Luigi Sabatini $^{3} \cdot$ Paola Berchialla $^{4}$. Veronica Sciannameo ${ }^{4}$ - Eugenio Graziano ${ }^{1} \cdot$ Alessandro Massè $^{2,3}$
}

Received: 14 August 2021 / Accepted: 12 January 2022 / Published online: 19 February 2022

(c) The Author(s) 2022

\begin{abstract}
Purpose Total knee arthroplasty (TKA) has experienced exponential growth over the last decade, including increasingly younger patients with high functional demands. Highly crosslinked polyethylene (HXLPE) has been proven effective in reducing osteolysis and loosening revisions while improving long-term survival and performance in total hip arthroplasty; nevertheless, this superiority is not demonstrated in TKA. The aim of this systematic review and meta-analysis was to examine whether HXLPE improved overall survival and postoperative functional and radiological outcomes compared to conventional polyethylene (CPE) in TKA.

Methods According to the Preferred Reporting Items for Systematic Reviews and Meta-Analyses (PRISMA) guideline, a literature search of five databases (PubMed, Medline, Scopus, Science Direct and Embase) was made. A PICOS model was performed. The initial screening identified 2541 studies. Each eligible clinical article was analysed according to the Oxford Centre for Evidence-Based Medicine 2011 Levels of Evidence (LoE). Only randomised clinical trials (RCTs) of LoE 1 and 2 were included. The methodological quality of the articles was assessed using the Risk of Bias 2 (RoB 2) tool.

Results Six clinical studies were included in the final study. This systematic review and meta-analysis were registered on the International Prospective Register of Systematic Reviews (PROSPERO). A total of 2285 knees were included. Eight outcomes (total reoperations, reoperations for prosthesis loosening and infections, radiolucent lines, osteolysis, mechanical failure, postoperative KSS knee score and function score) were analysed. For none of them, a statistically significant difference was found about the superiority of HXLPE over CPE $(p>0.05)$.

Conclusions There were no statistically significant differences between HXLPE and CPE for TKA concerning clinical, radiological, and functional outcomes; nevertheless, HXLPE did not show higher failure rates or complications and can be safely used for TKA.

Level of evidence II.
\end{abstract}

Keywords Polyethylene $\cdot$ CPE $\cdot$ UHMWPE $\cdot$ Crosslinked $\cdot$ Knee $\cdot$ Total knee arthroplasty $\cdot$ Meta-analysis

Francesco Bosco

francesco.bosco532@edu.unito.it

Alessandro Bistolfi

abistolfi@asl.at.it; a.bistolfi@ libero.it

1 Orthopaedics and Traumatology, Ospedale Cardinal Massaia Asti, via Conte Verde 125, 14100 Asti, Italy

2 University of the Studies of Turin, Turin, Italy

3 AO Città della Salute e della Scienza, Turin, Italy

4 Department of Clinical and Biological Sciences, University of Torino, Turin, Italy

$\begin{array}{ll}\text { Abbreviations } \\ \text { UHMWPE } & \text { Ultra-high molecular weight polyethylene } \\ \text { TKA } & \text { Total knee arthroplasty } \\ \text { HXLPE } & \text { Highly crosslinked polyethylene } \\ \text { CPE } & \begin{array}{l}\text { Conventional polyethylene } \\ \text { PRISMA }\end{array} \\ & \begin{array}{l}\text { Preferred Reporting Items for Systematic } \\ \text { Reviews and Meta-Analyses }\end{array} \\ \text { LoE } & \begin{array}{l}\text { Oxford Centre for Evidence-Based Medi- } \\ \text { cine 2011 Levels of Evidence }\end{array} \\ \text { RCTs } & \text { Randomised clinical trials }\end{array}$

Abbreviations

UHMWPE

HXLPE

Total knee arthroplasty

Highly crosslinked polyethylene

Conventional polyethylene

PRISMA

Reviews and Meta-Analyses

cine 2011 Levels of Evidence

$\mathrm{RCTs}$ 


$\begin{array}{ll}\text { RoB } 2 & \text { Risk of Bias 2 } \\ \text { PROSPERO } & \begin{array}{l}\text { International Prospective Register of Sys- } \\ \text { tematic Review } \\ \text { Mononuclear phagocyte system }\end{array} \\ \text { MPS } & \begin{array}{l}\text { Total hip arthroplasty } \\ \text { THA }\end{array} \\ \text { PICOS } & \begin{array}{l}\text { Patient, intervention, comparison, out- } \\ \text { comes, study design model }\end{array} \\ \text { BMI } & \text { Body mass index } \\ \text { KSS } & \text { Knee Society Score } \\ \text { CI } & \text { Confidence interval } \\ \text { IRR } & \text { Incidence rate ratio } \\ \text { SMD } & \text { Standardised mean difference } \\ \text { RTKA } & \text { Revision total knee arthroplasty } \\ \text { WOMAC } & \text { Western Ontario and McMaster Universi- } \\ & \text { ties Osteoarthritis Index } \\ \text { ROM } & \text { Range of motion } \\ \text { UCLA } & \text { University of California Los Angeles } \\ \text { LEAS } & \text { Lower extremity activity score } \\ \text { CR } & \text { Cruciate-retaining } \\ \text { PS } & \text { Posterior stabilised }\end{array}$

\section{Introduction}

Total knee arthroplasty (TKA) is the most common joint arthroplasty in North America and the second most common in Europe [35]. Therefore, this situation has led to new materials to improve the performance and durability of prosthetic implants.

One of the main factors affecting the long-term survival of a TKA is polyethylene wear-related osteolysis as a cause of aseptic loosening [3, 46, 52]. Furthermore, the particle sizes of polyethylene have been correlated to their biological activity; in particular, smaller particle sizes exhibited greater reactivity $[14,16,19,21]$.

As a result of the success of THA, great interest has been expressed in applying highly crosslinked polyethylene (HXLPE) to TKA [4, 8, 18, 37, 48]. Promising results supporting HXLPE in TKA have emerged from in vitro studies $[43,44]$; the same benefits have not yet been confirmed in in vivo studies [16, 20,49]. Several clinical studies have reported conflicting results regarding the superiority of HXLPE over CPE in TKA [17, 24, 39]. In addition, knee and hip joints present different tribological and kinematic characteristics. Polyethylene wear is more significant in TKA than in THA, while on the contrary, mechanical stresses are higher on tibial liners than on acetabular cups [5, 8, 28]. Therefore, since the crosslinking process of polyethylene determines a reduction of the mechanical properties, it may also increase the risk of tibial insert fracture $[36,40]$.

The aim of our systematic review and meta-analysis of randomised clinical trials (RCTs) was to evaluate whether HXLPE improved overall survivorship and postoperative functional and radiological outcomes compared with CPE in TKA since its introduction or, on the contrary, if HXLPE determined a higher risk of revisions than CPE.

\section{Methods}

\section{Research question}

The Preferred Reporting Items for Systematic Reviews and Meta-Analyses (PRISMA) checklist was used to perform this systematic review and meta-analysis [33]. The possible clinical and radiological improvements have been researched using HXLPE over CPE in TKA. Four authors (FB, CF, FG and MV) searched and evaluated the articles independently to avoid possible bias. In discrepancies, a fifth author (AB) was consulted to resolve any additional uncertainties. The Patient, Intervention, Comparison, Outcomes, and Study (PICOS) design was used to frame and answer clinical questions according to the PRISMA checklist [33]: patient $(\mathrm{P})$, patients who had undergone primary TKA; intervention (I), HXLPE tibial insert in TKA; comparison (C), CPE tibial insert in TKA; outcomes $(\mathrm{O})$, clinical, functional, and radiographic characteristics of the postoperative results of HXLPE compared with CPE in TKA; Study design model (S), RCTs.

\section{Inclusion criteria}

The inclusion criteria of the studies examined were "articles published in the English language, studies published within the last 15 years and with a minimum follow-up of 1 year, only RCTs with LoE 1 and 2, the full-text of the articles were available, and participants underwent primary TKA using HXLPE or CPE". "Biochemical and in vitro studies, case reports, editorials, book chapters, technical reports, preclinical studies, and review articles" were excluded from the research. Studies about human subjects were exclusively considered.

\section{Search strategy and study screening}

Literature research in five databases (PubMed, Medline, Scopus, Science Direct, and Embase) was performed using the following MeSH terms: [(knee replacement) OR (knee arthroplast*) OR (knee revision) OR (TKA) OR (TKR)) AND ((polyethylene) OR (crosslink) OR (CPE) OR (UHMWPE) OR (HXLPE)]. The research was limited from January 2005 to September 2021. A total of 2724 studies were identified through the database searches. After exclusion of duplicates, 1989 studies were included, of these, 1976 were excluded after examining the title and abstract. After the full-text evaluation 
for eligibility of these 13 studies, according to the inclusion and exclusion criteria, 6 clinical studies $[16,23$, $25,26,29,42]$ that evaluated differences in clinical and radiological outcomes using HXLPE versus CPE in TKA were included in the analysis. The bibliography for each article was reviewed to find additional relevant publications. The PRISMA flow chart for reporting study selection is shown in Fig. 1.

\section{Quality assessment}

According to the Oxford Centre for Evidence-Based Medicine 2011 Levels of Evidence (LoE) [9], each clinical article
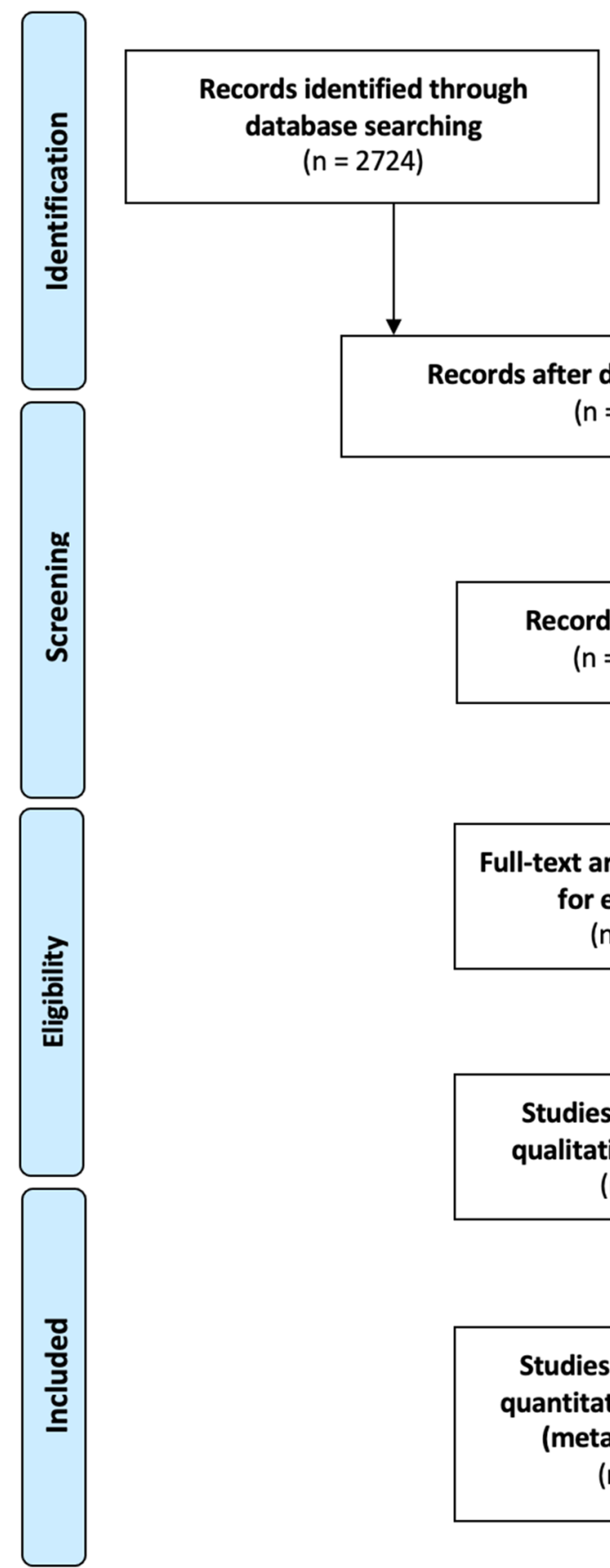

$\mathrm{n}=2724)$
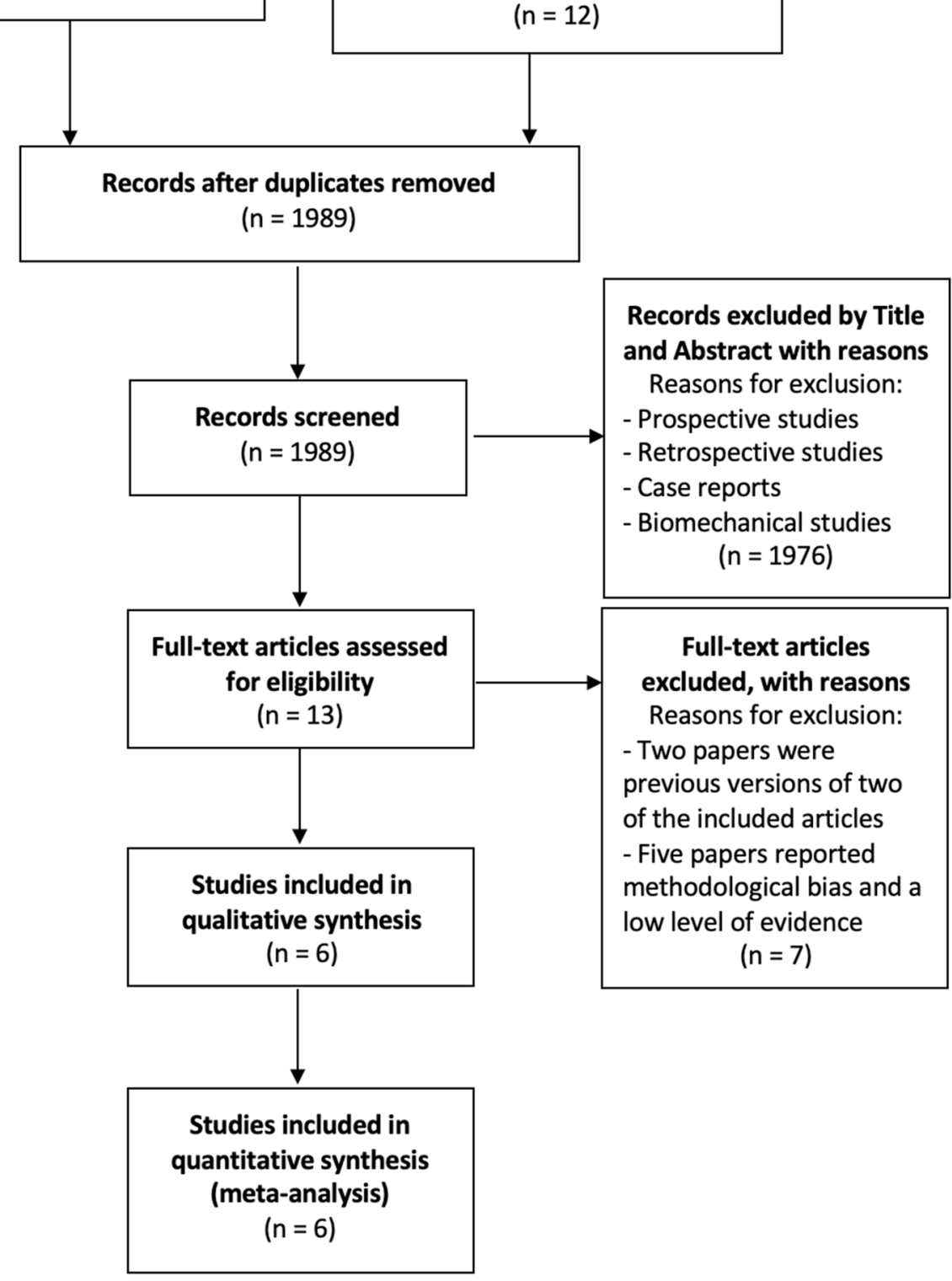

Additional records identified

through other sources

Reference list of included articles

$$
(n=12)
$$


was analysed. The $\mathrm{LoE}$ is an effective tool for assessing the strength of findings in research studies. Articles were graded from 1 to 5, where LoE 1 and 2 mean better study design, methodological quality, and lower risk of bias. The methodological quality of the articles was evaluated through the Risk of Bias 2 (RoB 2) tool [54] by four authors (Fig. 2). A fifth author resolved any cases of disagreement. The statistical analysis was performed by professional statisticians (PB and VS). All authors participated equally in the study design, manuscript preparation, and final review. This systematic review and meta-analysis were registered on the International Prospective Register of Systematic Reviews (PROSPERO), CRD42021231100 in March 2021 [53].

\section{Data extraction}

Data from the selected studies were inserted in a standard template and included the following study characteristics: author and publication year, number of knees, sample size mean age, sample size percentage sex, body mass index (BMI), follow-up of the studies, study design, total reoperations, reoperations for prosthesis loosening, reoperations for infections, radiolucent lines, osteolysis, mechanical failure related to the tibial polyethylene, and postoperative Knee Society Score (KSS) knee score and function score (Tables 1 and 2).

\section{Data analysis}

The DerSimonian and Laird random-effects model was used to pool estimates across studies. Average effect size and a $95 \%$ confidence interval (CI) was computed by the Jackson method. To estimate heterogeneity between studies, Cochran's Q test and Higgins' $I^{2}$ statistic were used. Values of $I^{2}$ of $0-24.9 \%, 25-49.9 \%, 50-74.9 \%$, and $>75 \%$ suggested no, low, moderate, or high heterogeneity, respectively. The pooled incidence rate ratio (IRR) and the pooled standardised mean difference (SMD) were considered statistically significant with a $p$ value $<0.05$. Finally, publication bias was visually inspected by funnel plots and tested by Egger's test. Statistical analyses were performed with R software, version 4.0.5 (2020; R Core Team, Vienna, Austria).

\section{Results}

A total of 2285 knees were analysed during a mean followup of $63.7 \pm 53.7$ months. The main demographic characteristics, such as age, percentage of males and females, and BMI, are reported in Table 1.

The outcomes total reoperations, reoperations for prosthesis loosening, reoperations for infections, radiolucent lines, osteolysis, mechanical failures, and postoperative KSS knee score and function score were examined (Table 2). A metaanalysis was performed for seven of these parameters, while it was not possible for the outcome of "mechanical failure" because none of the studies reported mechanical failures specifically related to the tibial polyethylene. For each outcome, the analysis did not show any significant publication bias effect. No significant heterogeneity was observed in the statistical analysis results for each outcome analysed in the included studies [16, 23, 25, 26, 29, 42]. There was no statistically significant difference found regarding the superiority of HXLPE over CPE for all outcomes assessed above $(p>0.05)$ (Figs. 3, 4, 5, 6, 7, 8, 9).

\section{Discussion}

The most important finding of the present study was a tendency towards the clinical and radiographic superiority of HXLPE over CPE, although it was not statistically significant for all outcomes. This finding could be relevant from a

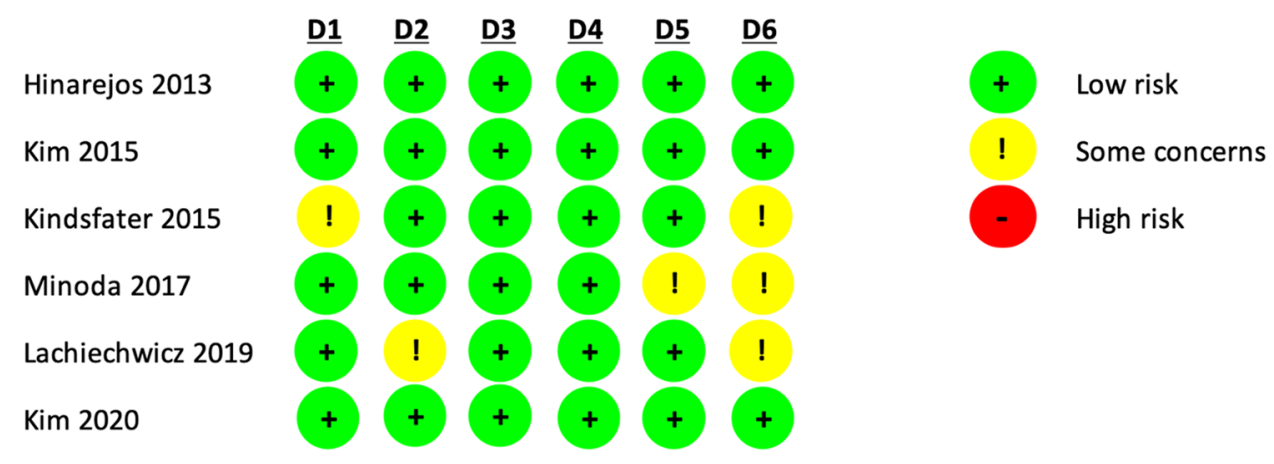

Fig. 2 Risk of bias conformed by the Cochrane Handbook for Systematic Reviews of Interventions. The quality and risk of bias of

$D 1$ randomisation process, $D 2$ Deviations from the intended interventions, D3 missing outcomes data, D4 measurement of the outcome, $D 5$ Selection of the reported result, $D 6$ overall 


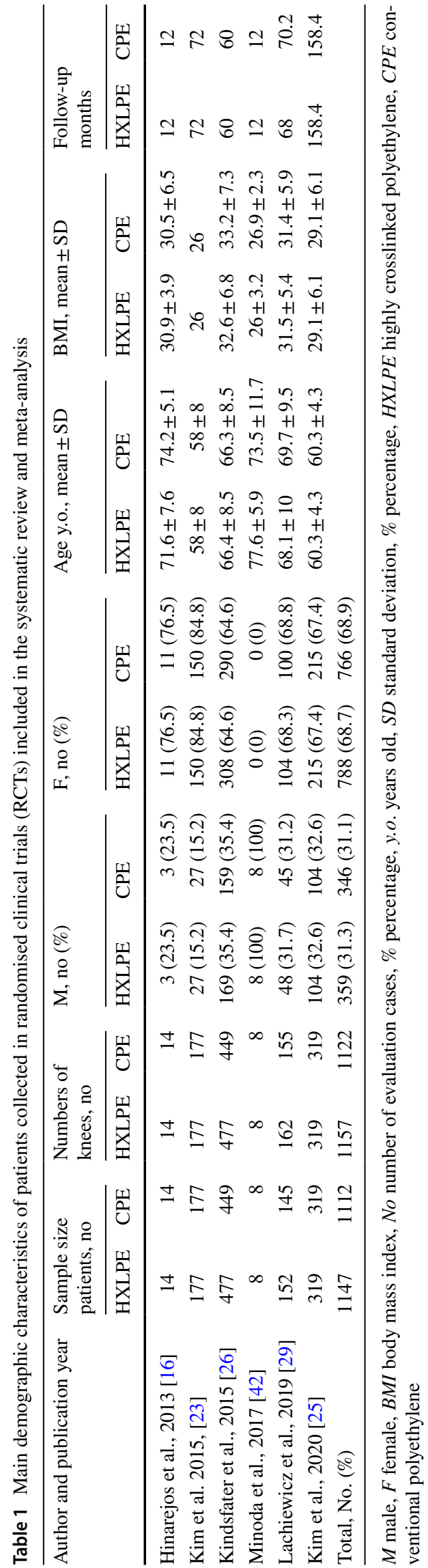

clinical point of view, because it may allow the safe use of crosslinked polyethylene for TKA.

According to the literature, the main cause of early revision is a prosthetic infection, whereas the main cause of late revision is aseptic loosening [10,11,27]. Revision total knee arthroplasty (RTKA) is a highly demanding procedure, with both high complication and postoperative failure rates [58]. Therefore, it is crucial to consider every prognostic factor that could predict a higher or lower risk of revision, as in this specific case, the performance and durability of the tibial polyethylene liner.

Regarding aseptic loosening, it is well known that the longevity of the implant is closely related to the wear of the polyethylene component, which leads to debris and subsequently to aseptic loosening with the need for revision $[6,12]$. It is also essential to adopt all strategies that could reduce the infection rate. A recent analysis examining the risk of infection with alternative bearing surfaces in TKA reported that HXLPE had a 26\% lower revision risk for infection than CPE [56]. Furthermore, the capability of the polyethylene substrate to avoid bacterial adhesion and biofilm formation could also play a role in infection risk [2]. It has been demonstrated that HXLPE has potentially greater resistance to bacterial adhesion and biofilm formation than CPE [1]. For these reasons, HXLPE has been adopted in TKA. In a recent meta-analysis, which considered national registries, Gkiatas et al. showed that patients in whom HXLPE had been implanted were less likely to be revised following aseptic loosening than those in whom CPE had been implanted. Regarding the overall revision rate, no significant difference was found between the two types of implanted polyethylene [15]. However, our quantitative analysis showed a lower revision rate in the HXLPE group compared to that in the CPE group for infection and aseptic loosening, although this finding was statistically insignificant.

Other issues regard periprosthetic osteolysis, with rates after TKA ranging from 5 to $20 \%$ over a follow-up period of 5-15 years, and radiolucent lines [30, 31, 46]. In their metaanalyses, Yu et al. and Gkiatas et al. [15, 57] reported a low incidence of osteolysis comparing HXLPE with CPE. The authors supposed that this difference could be related to the shorter follow-up period (2-6 years) of the studies included in their meta-analysis. Our results found that this low incidence of osteolysis among the two groups was unchanged over the long-term follow-up (60-158.4 months).

From a biochemical perspective, HXLPE is more resistant than CPE to adhesive and abrasive wear, although it is associated with weaker mechanical properties, including lower toughness, ductility, and fatigue fracture resistance [7, 47, 50]. The superior performance, in terms of wear resistance, of HXLPE in THA has led to its use in TKA. On the contrary, previous studies $[22,32,36,51]$ have shown that 


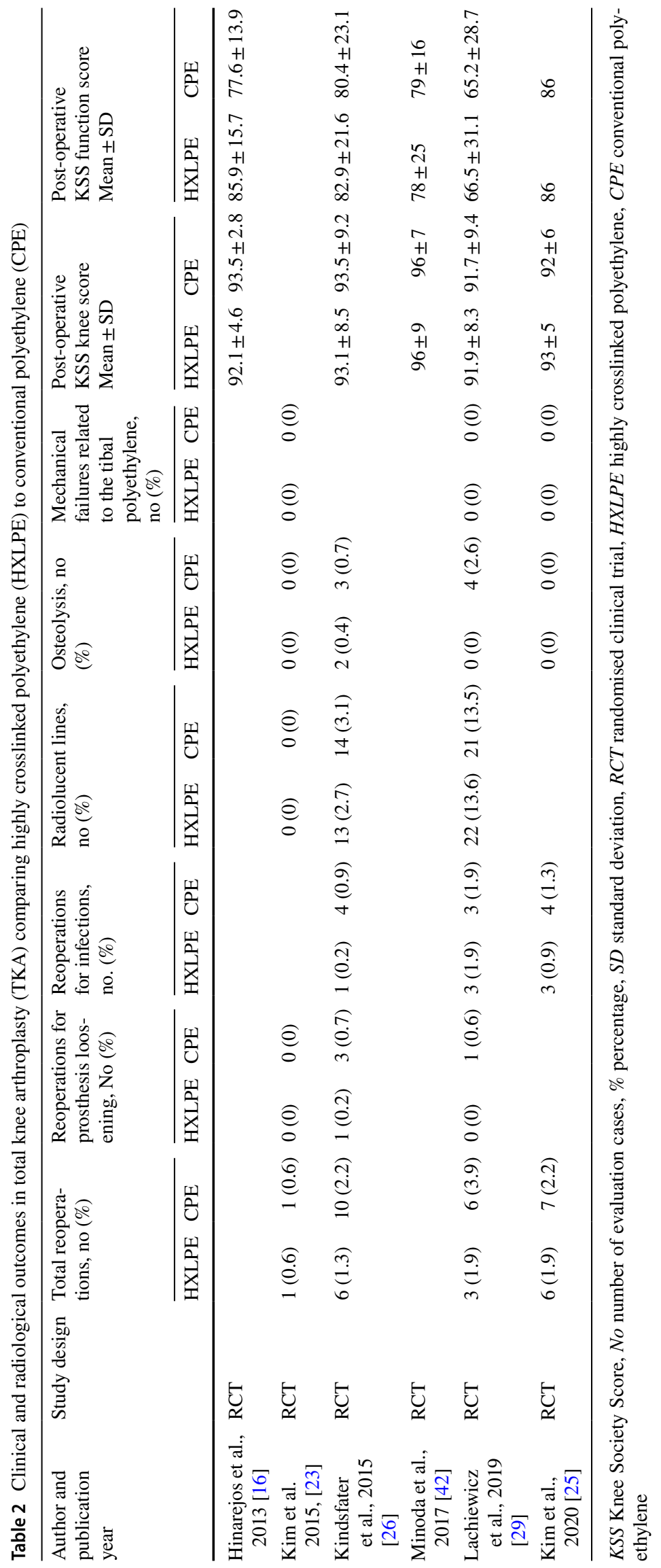




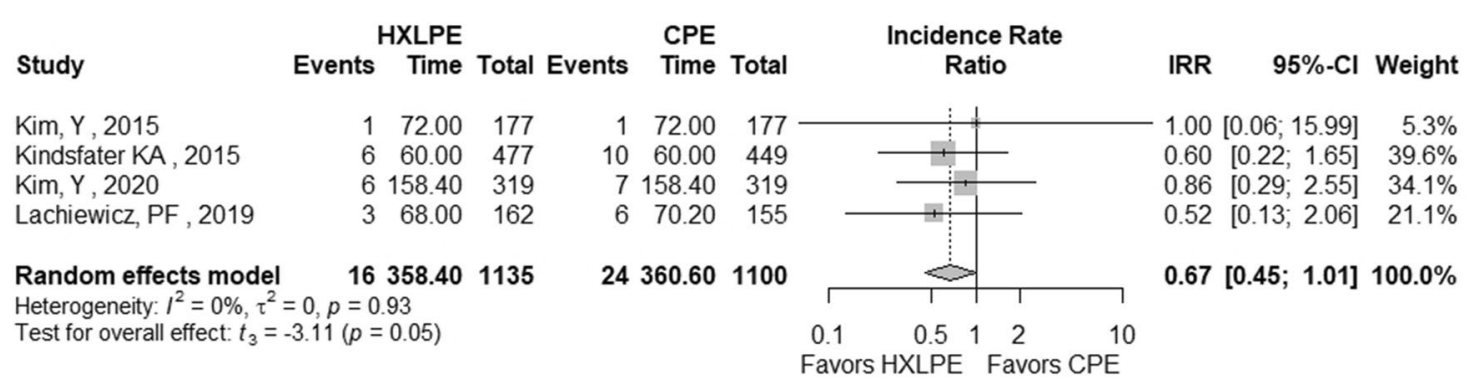

Fig. 3 Total reoperations. $H X L P E$ highly crosslinked polyethylene, $C P E$ conventional polyethylene, IRR incidence rate ratio, $C I$ confidence interval, $p p$ value

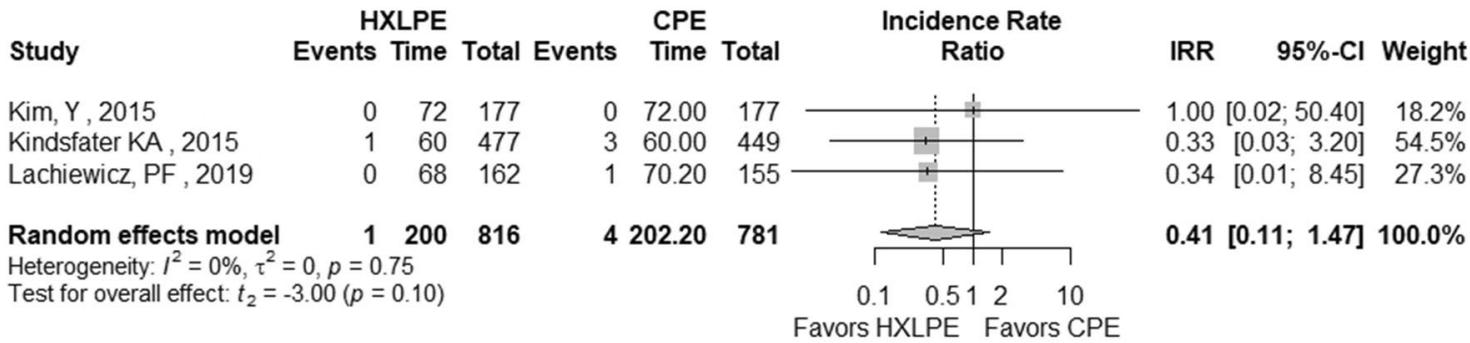

Fig. 4 Reoperations for prosthesis loosening. HXLPE highly crosslinked polyethylene, $C P E$ conventional polyethylene, IRR incidence rate ratio, $C I$ confidence interval, $p p$ value

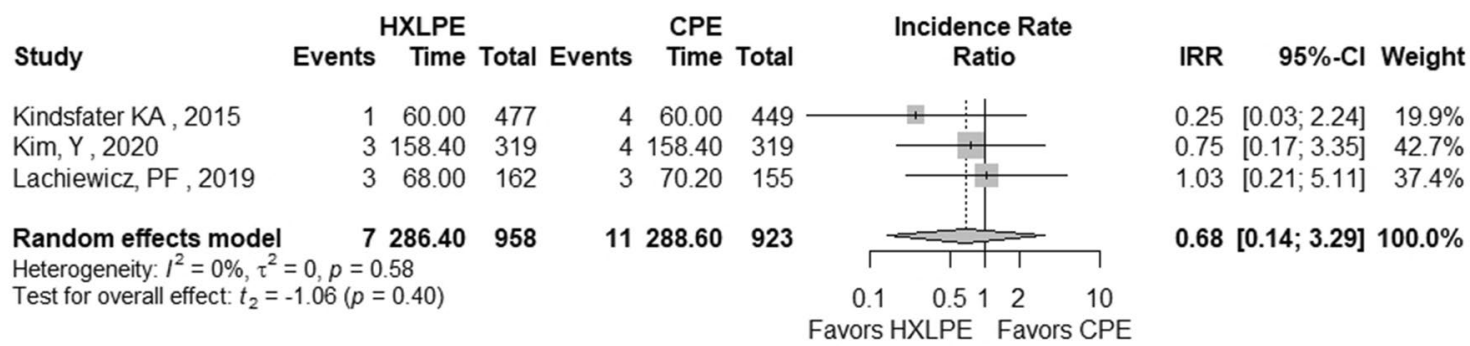

Fig. 5 Reoperations for infections. $H X L P E$ highly crosslinked polyethylene, $C P E$ conventional polyethylene, $I R R$ incidence rate ratio, $C I$ confidence interval, $p p$ value

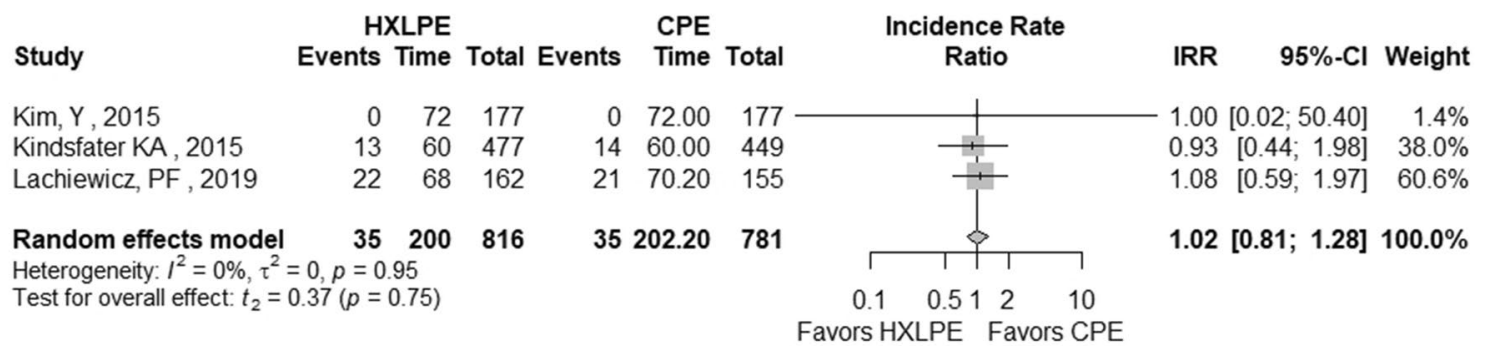

Fig. 6 Radiolucent lines. HXLPE highly crosslinked polyethylene, $C P E$ conventional polyethylene, $I R R$ incidence rate ratio, $C I$ confidence interval, $p$ p value 


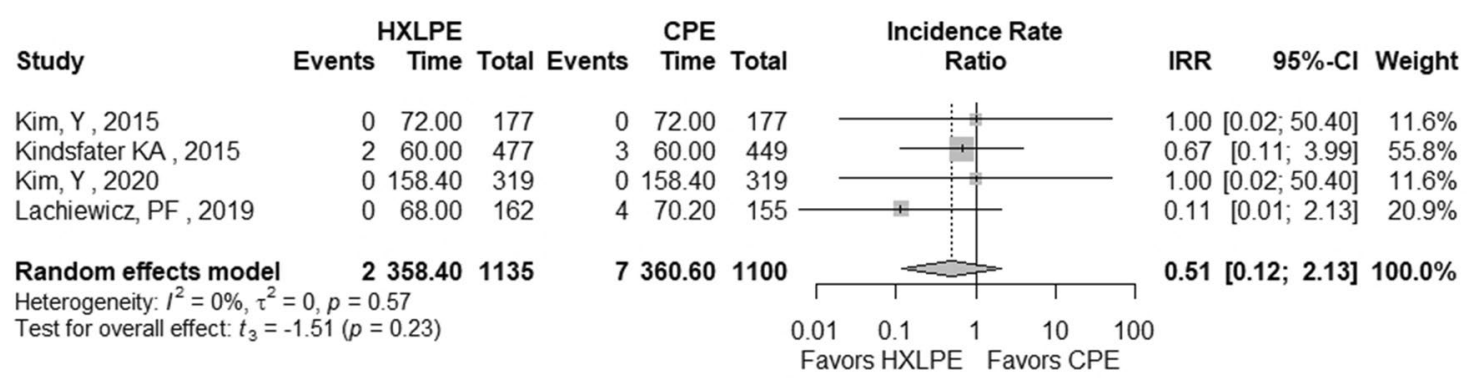

Fig. 7 Osteolysis. HXLPE highly crosslinked polyethylene, $C P E$ conventional polyethylene, IRR incidence rate ratio, $C I$ confidence interval, $p p$ value

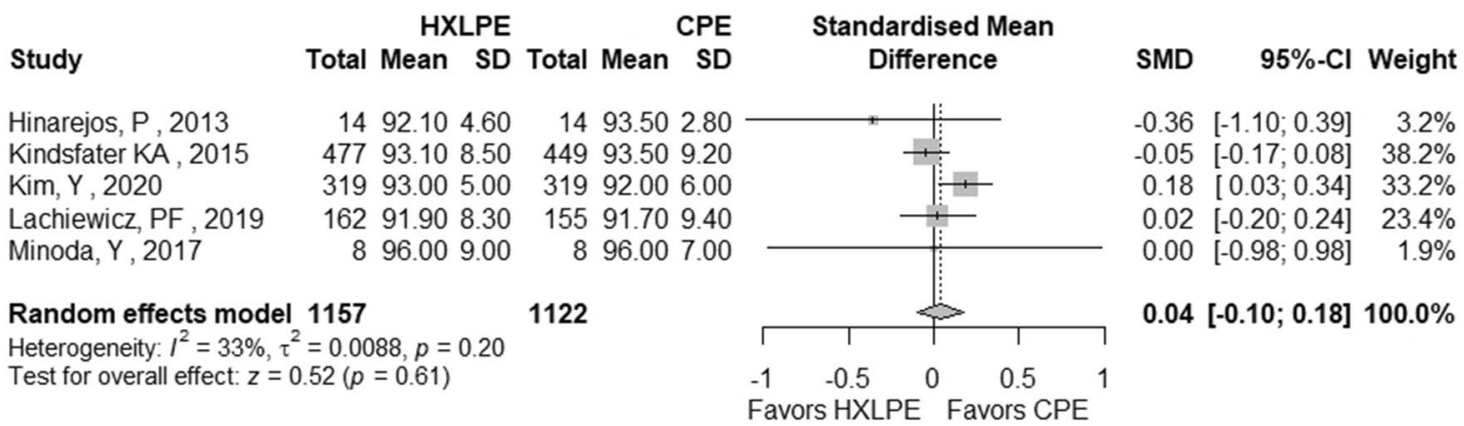

Fig. 8 Postoperative KSS knee score. KSS Knee Society Score, HXLPE highly crosslinked polyethylene, CPE Conventional Polyethylene, SMD standardised mean difference, $C I$ confidence interval, $p p$ value

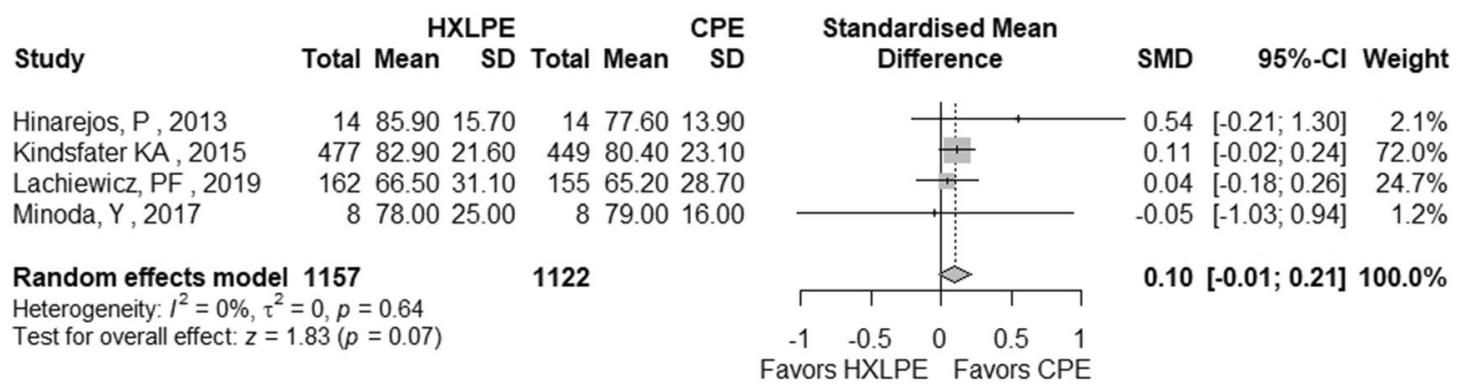

Fig. 9 Postoperative KSS function score. KSS Knee Society Score, HXLPE highly crosslinked polyethylene, CPE Conventional Polyethylene, $S M D$ standardised mean difference, $C I$ confidence interval, $p p$ value

HXLPE could lead to mechanical failure in TKA, and one of the reasons attributed to the failure of HXLPE in TKA is that wear mechanisms in the knee are not the same as those in the hip [5, 24]. Nevertheless, in favour of HXLPE, Yu et al. and Gkiatas et al. [15, 57], in their meta-analyses, found no mechanical failures for both polyethylene groups, as well as in the results of the studies included in our research where, again, no mechanical failures were reported [23, 25, 29]. Therefore, HXLPE appears to be as safe as CPE in TKA.

In the literature, contradictory evidence is reported about the superiority of HXLPE over CPE in TKA regarding clinical and functional results $[38,41]$. Between the different validated clinical and functional scores, the most widely used is the KSS, consisting of two sections: the knee score and function score [34]. The data analysis revealed almost comparable results between the two types of polyethylene in the KSS knee score, although HXLPE tended to be superior to CPE in the KSS function score, despite being statistically insignificant. Other clinical and functional scores [34] were also described between the studies included, but it was not possible to perform a quantitative analysis. Kindsfater et al. [26] observed similar Western Ontario and McMaster 
Universities Osteoarthritis Index (WOMAC) [13] values in the postoperative period between the two types of liners compared. Minoda et al. [42] did not find a benefit in the use of HXLPE over CPE in either range of motion (ROM) or University of California Los Angeles (UCLA) activity score [45] in the postoperative period. Lachiewicz et al. [29], in their study, found similar results comparing the lower extremity activity score (LEAS) [55] in the two polyethylene groups. Kim et al. [25], although they reported better postoperative outcomes in the HXLPE group, also find statistically insignificant differences in the WOMAC, ROM, UCLA activity score and patient satisfaction.

Regardless of the score used, no clear postoperative clinical and functional superiority of HXLPE over CPE was found in the studies analysed. In our opinion, the clinical performance is more strictly related to other factors, such as implant design, alignment, and surgical technique, than to the material itself, which benefits may be evident in other aspects (such as reduced wear, mechanical failures and fractures and more extended durability).

This meta-analysis presents limitations that need to be considered. These were mainly related to the limited number of included studies; Minoda et al. [42] and Hinarejos et al. [16] had small sample sizes that could provide a lower statistical analysis. Additional clinical studies with larger samples of patients will be necessary to further evaluate the superiority of HXLPE over CPE in TKA. Furthermore, two designs produced by different brands were implanted in the studies analysed: cruciate-retaining (CR) and posterior stabilised (PS). Both designs lead to different kinematics in TKA. These could result in different forces being applied to the polyethylene liner and consequently may produce different wear. Moreover, a quantitative analysis was not possible for one of the outcomes studied, mechanical failure, because it was not observed in any of the studies examined. Finally, a wide variety of follow-ups with a range of 12-158.4 months was reported in the studies included in this meta-analysis. A more homogeneous clinical follow-up would improve the validity of the data.

Previous studies $[15,57]$ and our meta-analysis have not shown a statistically significant superiority of HXLPE over CPE, although this paper has shown a tendency of the superiority of HXLPE over CPE. Further studies would be helpful to corroborate these findings to improve TKA outcomes.

\section{Conclusions}

This systematic review and meta-analysis showed statistically insignificant differences between HXLPE and CPE for TKA regarding clinical, radiological, and functional outcomes. The superiority of HXLPE over CPE remains unproven; nevertheless, it did not show higher rates of failure or complications with respect to the standard material and, considered the superiority demonstrated in laboratorystudies, it could be used for TKA.

Author contributions $\mathrm{AB}$ has made substantial contributions to conception and design, or acquisition of data, or analysis and interpretation of data, has been involved in drafting the manuscript or revising it critically for important intellectual content, has given final approval of the version to be published, and agree to be accountable for all aspects of the work in ensuring that questions related to the accuracy or integrity of any part of the work are appropriately investigated and resolved. FG has made substantial contributions to analysis and interpretation of data and has been involved in drafting the manuscript. FB has made substantial contributions to conception and design and has been involved in drafting the manuscript. CF has made substantial contributions to acquisition of data. MV has made substantial contributions to acquisition of data. LS has made substantial contributions to conception and design and has been involved in drafting the manuscript. PB has made substantial contributions to conception, analysis and interpretation of data and has been involved in drafting the manuscript. VS has made substantial contributions to conception, analysis and interpretation of data. EG has made substantial contributions to conception and design. AM has made substantial contributions to conception and design.

Funding No funding has been received for this study.

\section{Declarations}

Conflict of interest The authors have no conflict to declare. No benefits in any form have been received or will be received from a commercial party related directly or indirectly to the subject of this article.

Ethical approval The study has been conducted according to the ethical standards.

Informed consent No patients were involved in this study; hence, informed consent in not required.

Open Access This article is licensed under a Creative Commons Attribution 4.0 International License, which permits use, sharing, adaptation, distribution and reproduction in any medium or format, as long as you give appropriate credit to the original author(s) and the source, provide a link to the Creative Commons licence, and indicate if changes were made. The images or other third party material in this article are included in the article's Creative Commons licence, unless indicated otherwise in a credit line to the material. If material is not included in the article's Creative Commons licence and your intended use is not permitted by statutory regulation or exceeds the permitted use, you will need to obtain permission directly from the copyright holder. To view a copy of this licence, visit http://creativecommons.org/licenses/by/4.0/.

\section{References}

1. Banche G, Bracco P, Allizond V, Bistolfi A, Boffano M, Cimino A et al (2015) Do crosslinking and vitamin E stabilization influence microbial adhesions on UHMWPE-based biomaterials? Clin Orthop 473(3):974-986

2. Banche G, Bracco P, Bistolfi A, Allizond V, Boffano M, Costa L et al (2011) Vitamin E blended UHMWPE may have the 
potential to reduce bacterial adhesive ability. J Orthop Res 29(11):1662-1667

3. Bistolfi A, Bellare A (2011) The relative effects of radiation crosslinking and type of counterface on the wear resistance of ultrahigh-molecular-weight polyethylene. Acta Biomater 7(9):3398-3403

4. Bistolfi A, Giustra F, Bosco F, Sabatini L, Aprato A, Bracco P et al (2021) Ultra-high molecular weight polyethylene (UHMWPE) for hip and knee arthroplasty: the present and the future. J Orthop 25:98-106

5. Bistolfi A, Turell MB, Lee YL, Bellare A (2009) Tensile and tribological properties of high-crystallinity radiation crosslinked UHMWPE. J Biomed Mater Res 90(1):137-144

6. Bracco P, Bellare A, Bistolfi A, Affatato S (2017) Ultra-high molecular weight polyethylene: influence of the chemical, physical and mechanical properties on the wear behaviour. A review. Materials (Basel) 10(7):791

7. Bradford L, Baker D, Ries MD, Pruitt LA (2004) Fatigue crack propagation resistance of highly crosslinked polyethylene. Clin Orthop 429:68-72

8. Brown TS, Van Citters DW, Berry DJ, Abdel MP (2017) The use of highly crosslinked polyethylene in total knee arthroplasty. Bone Jt J 99B(8):996-1002

9. Burns PB, Rohrich RJ, Chung KC (2011) The levels of evidence and their role in evidence-based medicine. Plast Reconstr Surg 128(1):305-310

10. Cook R, Davidson P, Martin R (2019) More than $80 \%$ of total knee replacements can last for 25 years. BMJ 367:15680

11. Evans JT, Walker RW, Evans JP, Blom AW, Sayers A, Whitehouse MR (2019) How long does a knee replacement last? A systematic review and meta-analysis of case series and national registry reports with more than 15 years of follow-up. Lancet 393(10172):647-654

12. Gallo J, Goodman SB, Konttinen YT, Wimmer MA, Holinka M (2013) Osteolysis around total knee arthroplasty: a review of pathogenetic mechanisms. Acta Biomater 9(9):80468058

13. Gandek B (2015) Measurement properties of the Western Ontario and McMaster Universities Osteoarthritis Index: a systematic review. Arthritis Care Res (Hoboken) 67(2):216-229

14. Gazzano E, Bracco P, Bistolfi A, Aldieri E, Ghigo D, Boffano M et al (2011) Ultra high molecular weight polyethylene is cytotoxic and causes oxidative stress, even when modified. Int J Immunopathol Pharmacol 24(1 Suppl 2):61-67

15. Gkiatas I, Karasavvidis T, Sharma AK, Xiang W, Malahias MA, Chalmers BP et al (2021) Highly cross-linked polyethylene in primary total knee arthroplasty is associated with a lower rate of revision for aseptic loosening: a meta-analysis of 962,467 cases. Arch Orthop Trauma Surg. https://doi.org/10.1007/s00402-02103887-z (published online ahead of print, 2021 Apr 13)

16. Hinarejos P, Piñol I, Torres A, Prats E, Gil-Gómez G, Puig-Verdie L (2013) Highly crosslinked polyethylene does not reduce the wear in total knee arthroplasty: in vivo study of particles in synovial fluid. J Arthroplasty 28(8):1333-1337

17. Hodrick JT, Severson EP, McAlister DS, Dahl B, Hofmann AA (2008) Highly crosslinked polyethylene is safe for use in total knee arthroplasty. Clin Orthop 466(11):2806-2812

18. Inacio MC, Cafri G, Paxton EW, Kurtz SM, Namba RS (2013) Alternative bearings in total knee arthroplasty: risk of early revision compared to traditional bearings: an analysis of 62,177 primary cases. Acta Orthop 84(2):145-152

19. Ingham E, Fisher $J$ (2005) The role of macrophages in osteolysis of total joint replacement. Biomaterials 26(11):1271-1286

20. Iwakiri K, Minoda Y, Kobayashi A, Sugama R, Iwaki H, Inori F et al (2009) In vivo comparison of wear particles between highly crosslinked polyethylene and conventional polyethylene in the same design of total knee arthroplasties. J Biomed Mater Res 91(2):799-804

21. Jacobs JJ, Roebuck KA, Archibeck M, Hallab NJ, Glant TT (2001) Osteolysis: basic science. Clin Orthop 393:71-77

22. Jung KA, Lee SC, Hwang SH, Kim SM (2008) Fracture of a second-generation highly cross-linked UHMWPE tibial post in a posterior-stabilized scorpio knee system. Orthopedics 31(11):1137

23. Kim YH, Park JW, Kim JS, Lee JH (2015) Highly crosslinkedremelted versus less-crosslinked polyethylene in posterior cruciate-retaining TKAs in the same patients. Clin Orthop Relat Res 473(11):3588-3594

24. Kim YH, Park JW (2014) Comparison of highly cross-linked and conventional polyethylene in posterior cruciate-substituting total knee arthroplasty in the same patients. J Bone Jt Surg Am 96(21):1807-1813

25. Kim YH, Park JW (2020) Long-term assessment of highly crosslinked and compression-molded polyethylene inserts for posterior cruciate-substituting TKA in young patients: a concise follow-up of a previous report. J Bone Jt Surg Am 102(18):1623-1627

26. Kindsfater KA, Pomeroy D, Clark CR, Gruen TA, Murphy J, Himden S (2015) In vivo performance of moderately crosslinked, thermally treated polyethylene in a prospective randomized controlled primary total knee arthroplasty trial. J Arthroplasty 30(8):1333-1338

27. Kulshrestha V, Datta B, Mittal G, Kumar S (2019) Epidemiology of revision total knee arthroplasty: a single center's experience. Indian J Orthop 53(2):282-288

28. Kuzyk PR, Saccone M, Sprague S, Simunovic N, Bhandari M, Schemitsch EH (2011) Cross-linked versus conventional polyethylene for total hip replacement: a meta-analysis of randomised controlled trials. J Bone Jt Surg Br 93(5):593-600

29 Lachiewicz PF, O'Dell JA (2019) Prospective randomized trial of standard versus highly crosslinked tibial polyethylene in primary posterior-stabilized total knee arthroplasty: clinical and radiological follow-up at 2-11 years. Bone Jt J 101B(7 Suppl C):33-39

30. Lachiewicz PF, Soileau ES (2009) Fifteen-year survival and osteolysis associated with a modular posterior stabilized knee replacement. A concise follow-up of a previous report. J Bone Jt Surg Am 91(6):1419-1423

31. Lachiewicz PF, Soileau ES (2014) Fixation, survival and osteolysis with a modern posterior-stabilized total knee arthroplasty. J Arthroplasty 29(1):66-70

32. Lee CS, Chen WM, Kou HC, Lo WH, Chen CL (2009) Early nontraumatic fracture of the polyethylene tibial post in a NexGen LPS-Flex posterior stabilized knee prosthesis. J Arthroplasty 24(8):1292.e5-9

33. Liberati A, Altman DG, Tetzlaff J, Mulrow C, Gøtzsche PC, Ioannidis JP et al (2009) The PRISMA statement for reporting systematic reviews and meta-analyses of studies that evaluate health care interventions: explanation and elaboration. PLoS Med 6(7):e1000100

34. Liu CY, Li CD, Wang L, Ren S, Yu FB, Li JG et al (2018) Function scores of different surgeries in the treatment of knee osteoarthritis: a PRISMA-compliant systematic review and network-meta analysis. Medicine (Baltimore) 97(21):e10828

35. Lübbeke A, Silman AJ, Barea C, Prieto-Alhambra D, Carr AJ (2018) Mapping existing hip and knee replacement registries in Europe. Health Policy 122(5):548-557

36. Mauerhan DR (2003) Fracture of the polyethylene tibial post in a posterior cruciate-substituting total knee arthroplasty mimicking patellar clunk syndrome: a report of 5 cases. J Arthroplasty 18(7):942-945

37 McKellop H, Shen FW, Lu B, Campbell P, Salovey R (2000) Effect of sterilization method and other modifications on the wear resistance of acetabular cups made of ultra-high molecular 
weight polyethylene. A hip-simulator study. J Bone Jt Surg Am 82(12):1708-1725

38. Meneghini RM, Ireland PH, Bhowmik-Stoker M (2016) Multicenter study of highly cross-linked vs conventional polyethylene in total knee arthroplasty. J Arthroplasty 31(4):809-814

39. Meneghini RM, Lovro LR, Smits SA, Ireland PH (2015) Highly cross-linked versus conventional polyethylene in posterior-stabilized total knee arthroplasty at a mean 5-year follow-up. J Arthroplasty 30(10):1736-1739

40. Mestha P, Shenava Y, D'Arcy JC (2000) Fracture of the polyethylene tibial post in posterior stabilized (Insall Burstein II) total knee arthroplasty. J Arthroplasty 15(6):814-815

41. Minoda Y, Aihara M, Sakawa A, Fukuoka S, Hayakawa K, Tomita $\mathrm{M}$ et al (2009) Comparison between highly cross-linked and conventional polyethylene in total knee arthroplasty. Knee 16(5):348-351

42. Minoda Y, Hata K, Goto K, Itohara T, Nakamura H (2017) Sequentially annealed highly cross-linked polyethylene reduced in vivo wear particle generation in total knee arthroplasty. J Orthop Surg (Hong Kong) 25(2):2309499017718909

43. Muratoglu OK, Bragdon CR, Jasty M, O'Connor DO, Von Knoch RS, Harris WH (2004) Knee-simulator testing of conventional and cross-linked polyethylene tibial inserts. J Arthroplasty 19(7):887-897

44. Muratoglu OK, Bragdon CR, O'Connor DO, Perinchief RS, Jasty M, Harris WH (2002) Aggressive wear testing of a cross-linked polyethylene in total knee arthroplasty. Clin Orthop 404:89-95

45. Naal FD, Impellizzeri FM, Leunig M (2009) Which is the best activity rating scale for patients undergoing total joint arthroplasty? Clin Orthop 467(4):958-965

46. Naudie DD, Ammeen DJ, Engh GA, Rorabeck CH (2007) Wear and osteolysis around total knee arthroplasty. J Am Acad Orthop Surg 15(1):53-64

47. Naudie DD, Rorabeck CH (2004) Sources of osteolysis around total knee arthroplasty: wear of the bearing surface. Instr Course Lect 53:251-259

48. Oral E, Muratoglu OK (2011) Vitamin E diffused, highly crosslinked UHMWPE: a review. Int Orthop 35(2):215-223

49. Partridge TCJ, Baker PN, Jameson SS, Mason J, Reed MR, Deehan DJ (2020) Conventional versus highly cross-linked polyethylene in primary total knee replacement: a comparison of revision rates using data from the National Joint Registry for England, Wales, and Northern Ireland. J Bone Jt Surg Am 102(2):119-127

50. Renner L, Faschingbauer M, Boettner F (2015) Is there a rationale to use highly cross-linked polyethylene in posterior-stabilized total knee arthroplasty? Ann Transl Med 3(5):63

51. Ries MD (2005) Highly cross-linked polyethylene: the debate is over-in opposition. J Arthroplasty 20(4 Suppl 2):59-62

52. Sharkey PF, Hozack WJ, Rothman RH, Shastri S, Jacoby SM (2002) Insall Award paper. Why are total knee arthroplasties failing today? Clin Orthop 404:7-13

53. Sideri S, Papageorgiou SN, Eliades T (2018) Registration in the international prospective register of systematic reviews (PROSPERO) of systematic review protocols was associated with increased review quality. J Clin Epidemiol 100:103-110

54 Sterne J, Savović J, Page MJ, Elbers RG, Blencowe NS, Boutron I et al (2019) RoB 2: a revised tool for assessing risk of bias in randomised trials. BMJ 366:14898

55. Terwee CB, Bouwmeester W, van Elsland SL, de Vet HC, Dekker $\mathrm{J}$ et al (2011) Instruments to assess physical activity in patients with osteoarthritis of the hip or knee: a systematic review of measurement properties. Osteoarthr Cartil 19(6):620-633

56. Vertullo CJ, Lewis PL, Peng Y, Graves SE, de Steiger RN (2018) The effect of alternative bearing surfaces on the risk of revision due to infection in minimally stabilized total knee replacement: an analysis of 326,603 prostheses from the Australian Orthopaedic Association National Joint Replacement Registry. J Bone Jt Surg Am 100(2):115-123

57. Yu BF, Yang GJ, Wang WL, Zhang L, Lin XP (2016) Cross-linked versus conventional polyethylene for total knee arthroplasty: a meta-analysis. J Orthop Surg Res 11:39

58 Zanirato A, Cavagnaro L, Basso M, Divano S, Felli L, Formica M (2018) Metaphyseal sleeves in total knee arthroplasty revision: complications, clinical and radiological results. A systematic review of the literature. Arch Orthop Trauma Surg 138(7):993-1001

Publisher's Note Springer Nature remains neutral with regard to jurisdictional claims in published maps and institutional affiliations. 